\title{
Lying, Misleading, and Dishonesty
}

\author{
Alex Barber ${ }^{1}(\mathbb{0}$ \\ Received: 16 November 2018 / Accepted: 4 November 2019 / Published online: 14 November 2019 \\ () The Author(s) 2019
}

\begin{abstract}
An important moral category-dishonest speech-has been overlooked in theoretical ethics despite its importance in legal, political, and everyday social exchanges. Discussion in this area has instead been fixated on a binary debate over the contrast between lying and 'merely misleading' (that is, attempting to deceive someone without uttering a literal falsehood). Some see lying as a distinctive wrong; others see it as morally equivalent to deliberately omitting relevant truths, falsely insinuating, or any other species of attempted verbal deception. Parties to this debate have missed the relevance to their disagreement of the notion of communicative dishonesty. Communicative dishonesty need not take the form of a lie, yet its wrongness does not reduce to the wrongness of seeking to deceive. This paper therefore proposes a major shift of attention away from the lying/misleading debate and towards the topic of communicative dishonesty (or 'dishonesty' for short). Dishonesty is not a simple notion to define, however. It presupposes a difficult distinction between what is and is not expressed in a given utterance. This differs from the more familiar distinction between what is and is not said, the distinction at the heart of the lying/misleading debate. This paper uses an idea central to speech act theory to characterize dishonesty in terms of the utterer's communicative intentions, and applies the resulting definition to a variety of contexts.
\end{abstract}

Keywords Lying $\cdot$ Misleading $\cdot$ Deceiving $\cdot$ Honesty

English has an impressive array of phrases to describe speech intended to cause or sustain false belief, including 'duplicitous', 'disingenuous', 'deceptive', 'insincere', 'mendacious', 'misleading', 'dissembling', 'lying', and more. Which to use is often a merely stylistic matter, but behind this flexibility are distinctions with genuine ethical significance. My goal here is to reveal the importance of a category of wrong that has been overlooked in theoretical ethics, camouflaged in part by this terminological forest but also by the complexity of the terrain itself. I call this category

Alex Barber

alex.barber@open.ac.uk

1 Department of Philosophy, The Open University, Milton Keynes MK7 6AA, UK 
communicative dishonesty (or 'dishonesty' for short), and argue that it should be incorporated into the core repertoire of concepts we draw on when discussing verbal probity. ${ }^{1}$

The label 'dishonesty' comes as close as any to expressing the notion I have in mind and the resulting usage has a certain naturalness to it. For all that, this is not meant to be an exercise in making explicit the meaning of a familiar term. My approach will instead be to bring out the need we have for a certain kind of notion (Sect. 1), before showing how 'dishonesty', suitably defined, meets that need (Sect. 2). That this definition matches ordinary usage is argued for at the end of Sect. 2, but 'verbal insincerity' would be a fair alternative, as would coining a new term entirely if neither was a good fit. In Sect. 3 the notion is put to work in a variety of real-world professional and informal contexts.

The concept of dishonesty (in my usage ${ }^{2}$ ) has been overlooked in theoretical ethics because the relevant literature is hypnotized by the contrast between lying and merely seeking to mislead. Some hold that this 'lying/misleading' boundary has moral significance; others see lying as not importantly distinct from other attempts at verbal deception. In Sect. 1, I describe how the binary nature of this debate has led both sides to overlook a morally significant category (dishonesty) that is broader than lying, yet whose wrongness cannot be reduced to the wrongness of deception. An important implication of the present paper, then, is that this traditional debate is misconceived.

The core respect in which it is misconceived is in its focus on the boundary between saying and merely intimating, insinuating, etc. Our focus instead should be on the boundary between what is and is not expressed in a communicative act, irrespective of whether it is actually said. This is the boundary that becomes salient when we shift to thinking about dishonesty. We cannot assume without question that this boundary even exists, let alone that it is easily traced. Perhaps for this reason, relatively few attempts have been made to exploit the boundary in discussions of the ethics of communication. ${ }^{3}$ In Sect. 2, I draw on an idea central to speech act theory to produce a working account of what it is to express something (whether by saying or by insinuating), and from that a definition of dishonesty.

\footnotetext{
1 A 'category of wrong', here, means a set composed of all the acts possessing some particular (prima facie) wrong-making quality. The force of '(prima facie)' is to allow that lies, etc., can in some circumstances be merely pro tanto wrong, and in others perhaps not even that.

2 Discussions of '(dis)honesty' in other senses include Carson (2010: 257-265), for whom it is a character trait rather than a property of individual acts. Most discussions of the ethics of truthfulness use 'dishonest' fairly casually (e.g. Webber 2013: 659). Hawley (2012), Ch. 5 ('Honesty and dishonesty'), focuses on detection rather than the concept itself.

${ }^{3}$ Seen note 20 for some exceptions.
} 


\section{Lying and Misleading}

My goal in this first section, then, is to use the standard 'lying/misleading' debate as a platform from which to establish the need for a particular kind of notion, before developing and defining a notion that meets this need-dishonesty-in Sect. 2. I begin by setting out the debate on its own terms, with no mention of dishonesty. I then present a strong representative argument from each side: Jennifer Saul's case against the moral significance of the lying/misleading distinction, and Seana Valentine Shiffrin's case for the opposing view that lying is distinctively wrong. They are each partly right and partly wrong, but the right parts can be combined into a case for recognizing a new moral category.

\subsection{What the Lying/Misleading Debate is About}

The debate centres on a contrast best brought out using examples. (1) to (6) are pairs of utterances. In each, utterance (a) involves the speaker lying in the relevant sense, while utterance (b) does not, even though deception is always the goal.

(1) Here, the speaker is a job candidate, $\mathrm{Mr} \mathrm{H}$ is another applicant, and the audience is on the appointment committee.

(a) 'I heard that $\mathrm{Mr} \mathrm{H}$ was fired for selling commercially sensitive information.'

(b) 'I never realised $\mathrm{Mr} \mathrm{H}$ was fired for selling commercially sensitive information.'

Since realising something requires the truth of that something, (b) is not a lie.

(2) Here, the speaker is trying to persuade her audience that she was raised an orphan.

(a) 'When I was two, my parents went to the top of their high-rise and jumped off it.'

(b) 'When I was two, my parents went to the top of their high-rise and jumped.' In fact both parents are still alive, though they no longer own a roof trampoline. ${ }^{4}$

(3) X wants Y dead and has packed Y's parachute accordingly. Y asks: 'Did you pack my parachute properly?' $\mathrm{X}$ replies:

(a) 'Yes, I used the roll-packing method—-sensible in today's conditions.'

(b) 'Nooo. I just stuffed it in. [Rolls eyes.] Oh, and I tied a knot in it first.'

${ }^{4}$ Cf. Saul (2012b: 25-26, 116-118). 
(4) Since his persecutors are catching up, Athanasius turns his boat and approaches them in disguise. 'Have you seen Athanasius?' they ask. He replies:

(a) 'Yes, he is but an hour's journey upriver'

(b) 'He is near; make haste and you will soon pass him.' 5

(5) Kant wishes to deceive his neighbours into thinking he is leaving Königsberg. He places luggage outside his front door.

(a) He announces: 'As you can see, I am going on a journey.'

(b) He says nothing, leaving them to draw the inference. ${ }^{6}$

(6) An established professor wishes to push a brilliant student out of academia:

(a) 'Dear Sir, Ms. X is a mediocre student whose publications in so-called philosophy journals are an embarrassment to the profession.'

(b) 'Dear Sir, Ms. X's command of English is excellent, and her attendance at tutorials has been regular. Yours, etc. ${ }^{7}$

These contrasting pairs capture a sense of 'lying' according to which lying involves actually saying it. The 'lying/misleading' debate turns on whether actually saying it matters, morally speaking.

Before considering opposing positions in this debate, we need a working definition of lying, one that traces the distinction implied by the examples. Any off-theshelf definition will be controversial, and the flexibility of everyday usage means it will also involve an element of stipulation. With these qualifications in place, I propose the following:

Lying $=$ saying that $p$ when one knows $p$ to be untrue

The crucial phrase here is 'saying'. Other definitions containing 'saying' (or an equivalent: 'stating', 'asserting', etc.) could be just as good. Still, if only to see off hasty dismissals, and because this definition will feed into the definition of 'dishonesty' in Sect. 2, I will comment briefly on two other features.

Some will balk at the word 'knows'. Weakening it to 'believes' would allow us to categorize as a liar someone who says that $p$ while mistakenly believing not- $p$. But we can accommodate such cases by describing the speaker as attempting to lie, with culpability to match. There is, moreover, some advantage to using 'know' in that it captures a central feature of lying: that liars piggy-back illicitly on testimony, a method for transmitting knowledge. Liars typically present themselves to their

\footnotetext{
5 Cf. Reynolds 1889: 156-157. The example is a standard fixture in discussions of lying.

6 Cf. Kant (1997 [c.1784]: 202).

7 Cf. Grice (1989 [1967]: 33).
} 
audiences as a source of knowledge while being nothing of the kind. There is more to say on this, certainly, but I will assume it is not pertinent here. ${ }^{8}$

Others will insist on an additional condition: that the liar intends to deceive the audience into believing that $p$. We do not condemn actors as liars, after all. But we can accommodate this case by describing actors as acting as if they are saying, and so as not genuinely lying even on this definition. Moreover, requiring that liars intend to deceive the audience into believing that $p$ sometimes jars with ordinary usage. Imagine a conversation with someone who is oddly sceptical towards everything you say. For amusement you say you are a lighthouse keeper. You have no intention to trick your interlocuter into believing this as you know you will be disbelieved, yet it is natural to describe you as having decided to lie. (True, you have intended to deceive in some respects: even here you are falsely presenting yourself as trying to have them believe that you are a lighthouse keeper. But this intention to deceive is already built into your act of saying something you know to be false, so does not require an extra clause.) As with 'knows' there is more to be said about this controversy but it seems tangential in the present context. ${ }^{9}$

The inclusion of 'saying' is not tangential in the same way, since it is central to the lying/misleading debate. But what is saying? When the candidate in (1) utters (b) instead of (a), many would describe her as having 'as much as said it', or even as having actually said it. Before we can go any further we need a better delineation of the saying/not-saying boundary.

An obvious starting point is to treat saying something as a matter of exploiting the literal meaning of explicitly uttered words. Literal meaning is, however, a contested notion. Many theoretical linguists and philosophers of language doubt it is a useful category (e.g. Recanati 2004). Others disagree over what is and is not part of literal meaning. The controversy is rooted in disputes over the existence and nature of the semantics/pragmatics boundary. As is familiar from Paul Grice's ground-breaking work on implicature, it is intuitive to describe what a person means as sometimes coming apart from what their words mean. His 'faint praise' reference-letter example, the model for (6b) above, is a case in point. According to Grice, when this happens we extract what the speaker really means from what they say. What we say is given by the meaning of the words used ('semantics') and hearers extract the speaker's actual meaning from what they have said by applying various maxims-of relevance, of brevity, etc.- to the context ('pragmatics'). But after Grice's pioneering work, many began to argue that contextual considerations make a contribution even to what is said. That is, word meanings alone frequently fails to determine a truth-evaluable content. A typical utterance of (7), for example, would readily be taken as the utterer saying that they have not had breakfast that morning, despite this

\footnotetext{
${ }^{8}$ Belief views are adopted, usually not insistently, by Augustine (2002 [c.395]: §3, pp. 54-55), Fallis (2009: 33-34), Saul (2012b: 18), Webber (2013: 652), and Shiffrin (2014: 12-13). Merriam-Webster and the Oxford English Dictionary (current editions) require actual falsehood, as does Carson (2010: 30).

9 Augustine (2002 [c.395], $\$ 2-3$, pp. 54, 55-56) insists on an intention to deceive the audience into believing that $p$. Many recent authors do not, including Sorensen (2007), Fallis (2009), Carson (2010: 37), and Shiffrin (2014: 13n).
} 
restriction not being explicit; in contrast, an utterance of (8) would not normally be taken to come with such an unstated restriction built into what has been said.

(7) 'I have not had breakfast.'

(8) 'I have not been unfaithful.'

What such cases suggest is that words alone do not always determine what is being said. Contextual features also make a contribution. Some have even argued that this is the norm. ${ }^{10}$

Since I am not ultimately concerned with the lying/misleading contrast, I will not spend time pinning down the difference between saying and meaning-without-saying. Indeed, I suspect no robust statement can be given of the distinction, in which case the supposed moral contrast between lying and merely misleading is predicated on a false assumption. For the sake of the argument, however, I will assume that some account can be given of how to distinguish the contextual, pragmatic determinants of what is said from the pragmatic ingredients of mere insinuation and the like. I will simply follow Saul's suggestion, according to which context-specific contributions to a speaker's meaning are a part of what has been said only if the sentence alone, without those contributions, fails in that context to express any proposition, i.e. the sentence is not 'truth-evaluable'. To illustrate, consider case (2) above. Understanding someone as having jumped does not require any specification of what they have jumped off, on, over, into, etc. The speaker in (2b) therefore does not count as having said something false (or, therefore, as having lied). In contrast, were a child to utter 'I've finished' in the context of a conversation about homework, then even though he has not uttered the phase 'my homework', he does count as having said that he has finished his homework (and so, potentially, as having lied). This is because 'I've finished' lacks a truth-evaluable semantic content without some specification of what the finished thing is. In technical terms, the homework case merely involves contextual completion while (2b) involves contextual extension of an already truth-evaluable sentence (Saul 2012b: 66, following Bach 1994).

With this working understanding of saying (and so of lying) in hand, let us turn to the arguments for each side in the lying/misleading debate.

\subsection{A Case for Holding that Lying is not Distinctively Wrong (Saul)}

Many writers have seen the wrong of lying (when it is wrong, that is ${ }^{11}$ ) as something over and above the wrong of merely attempting to deceive. They include Athanasius and Kant, the subjects of examples (4) and (5) above. Athanasius used the careful language of (4b) in order to, as later commentators put it, respect the Eighth Commandment. Kant implies of (5b) not only that he has 'told no lie' but that his

\footnotetext{
${ }^{10}$ E.g. Cappelen and Lepore (2005). Cases like (7)-(8) abound in the semantics/pragmatics literature; see e.g. contributions to Stojanovic (2008).

11 When this qualification is omitted it is for simplicity; lying under the present definition can be a merely pro tanto wrong or even no wrong at all.
} 
behaviour is less objectionable (1997 [c.1784]: 202-203). In a trenchant rejection of this tradition, Saul claims that if for some reason you need to mislead someone, there is no moral gain to be had from the careful use of evasive language. You should 'just go ahead and lie'. Others have taken a comparable stand but I will focus on Saul's arguments. ${ }^{12}$

Nuances aside, her core case for the moral insignificance of the distinction between lying and other forms of deliberate verbal deception comes to this:

Premise 1 If the distinction matters, it matters because of a morally significant difference in either outcome or motive or method used.

Premise 2 There is no difference in outcome or motive, and the difference in method used is morally irrelevant.

Conclusion The distinction does not matter. ${ }^{13}$

Premise 1 seems plausible enough, as does the first conjunct of Premise 2. If we look at examples (1)-(6), there is no important difference in outcome or motive between the scenario pairs. ${ }^{14}$ What Saul says about method is more questionable, in ways that will be important later on. For one thing, she seems to overstate her case in a way I have corrected for in formulating Premise 2. In her book she appears to suggest that a difference in method will never be morally significant if the outcome and motive are morally equivalent. In discussing the moral acceptability of violent harm, for example, she writes:

[We] differentiate the morally acceptable violence from the morally unacceptable violence not by focusing on method of violence (knife, gun, fist, kick, etc.) but instead on the occasion for violence (e.g. self-defence or without provocation). This would be by far the more natural way to deal with the situation concerning deception: differentiate between permissible and impermissible deceptions according to their purpose-rather than according to their method. ... A norm focused on method of deception is utterly mysterious. (2012b: 85; see also 2012b: 69)

\footnotetext{
${ }^{12}$ Saul (2012b). The phrase 'just go ahead and lie' is from her (Saul 2012a), and appears in Adler (1997: 446). Williams (2002: 81) is, like Saul, critical of what he calls the fetishization of explicit assertion in discussions of truthfulness.

${ }^{13}$ See Chapter 4 of Saul (2012b). Something like Saul's argument is countenanced, and rejected, by Adler (1997: 438). His views are discussed briefly in Sect. 3 below. Saul, it should be said, has two caveats that I ignore here. First, she allows that a person who (wrongly) thinks that lying is worse than merely deceiving can reveal something bad about their character if they then lie instead of merely deceiving (2012b: 86-94). Second, she thinks that lying under oath can be worse than merely deceiving under oath (2012b: 95-97).

${ }^{14}$ One might quibble that the need to be cagey makes the deception easier to detect; but the distinctive wrongness of lies is not going to be very robust if it turns on detectability. Consider an even sneaker variant of (1b): 'I didn't realise until last night that Mr H was fired for selling commercially sensitive information.' As with (1b), 'realised' is factive; in addition, something can be true 'until last night' and remain true today. In practice this twofold trickery will be no easier to pick up on than the equivalent lie.
} 
A more plausible thought is that the method used is sometimes morally relevant and sometimes not. If I want your rarely-used bicycle, for example, it seems to matter, morally speaking, that I obtain it by asking rather than by taking it in the night, even if my motive and the outcome would be the same (we can assume you would not interpret the absence of your bicycle as the product of theft, for example). If my desire for your bicycle is strong and I suspect you would refuse if I asked for it, it does not follow that I may as well 'just go ahead and steal' (cf. Saul 2012a).

For this reason I have weakened Premise 2 to the claim that the specific difference in method used here-lying versus some other means of verbal deceptionis among those that lack moral significance. And on the face of it, we can agree with Saul here that it matters very little if a deception exploits the linguistic device of completion rather than extension. This difference seems less like the difference between persuading and stealing, and more like the difference between a gun and a dagger: morally trite. ${ }^{15}$

I conclude that Saul is right: lying is not a distinct moral category. We have still to consider Shiffrin's case for the opposing view, but when we do, I argue that this particular aspect of Saul's viewpoint withstands it. Saul does go wrong, however, in inferring without argument that lying is on the same moral footing as all cases of attempted verbal deception, as if the wrongness of a lie, when it is wrong, reduces to the wrongness of attempting to cause or sustain false belief. The alternative view I will defend treats all lies as instances of dishonesty, a morally significant category she overlooks, which is broader than lying yet not so broad as to include all cases of attempted verbal deception. An act of lying, when it is wrong, can be wrong for either or both of two reasons: because it is an attempt to deceive or because it is an act of dishonesty. This alternative view will emerge more clearly as we examine Shiffrin's position.

\subsection{A Case for Holding that Lying is Distinctively Wrong (Shiffrin)}

I noted that Saul overstates her case by claiming that a difference in method used is, in itself, morally insignificant. One reason for taking care on this point is the existence of a long tradition (to which Shiffrin contributes) of criticizing lying precisely because it exploits and debases a method, the method of communicating by linguistic exchange. If this tradition is correct, lying/misleading may after all be like theft/ persuasion and unlike stabbing/shooting.

An early instance of the idea can be found in the writing of the thirteenth-century Islamic scholar, Ibn al-Qayyim, who regards lying as the corrupted or dysfunctional use of language:

\footnotetext{
15 Jonathan Webber underestimates the force of this aspect of Saul's argument. He argues that, in his terminology, damaging one's credibility in assertion (by lying) also damages one's credibility in implicature, whereas damaging one's credibility in implicature (by falsely insinuating, say) need not damage one's credibility in assertion. He wrongly infers from this that liars should be met with 'greater opprobrium' (2013: 651) than false insinuators. But one can kill using a luger only by killing with a gun, while killing with a gun does not necessitate killing with a luger. It does not follow that killing with a non-luger is less heinous.
} 
[False lying] corrupts the very essence of the testimony, fatwa or report. ... The lying tongue is like some faculty that is no longer working; indeed it is even worse than that, for the most evil thing a man may possess is a lying tongue. $^{16}$

Some centuries later, Montaigne calls lying the one vice that must be 'beaten' out of children. His rationale for this strong attitude is brief but to the point:

We are men, and have ties upon one another, only through our word. ${ }^{17}$

His suggestion is that language-'our word'-gives us a system or means-a method-through which we can know one another's minds, ask for and make commitments, express views, and so forth. A lie is an assault on this system. There are ways to get others to believe a falsehood besides uttering an indicative sentence that expresses the falsehood. These may be criticisable, but they do not threaten 'our word' in the same way.

Kant's discussion of lying in Lectures on Ethics is a direct influence on Shiffrin. He writes:

In human social life, the principal object is to communicate our attitudes, and hence it is of the first importance that everyone be truthful in respect of his thoughts, since without that, social intercourse ceases to be of any value. ... [T] he liar destroys this fellowship [among men], and hence we despise a liar .... Whoever may have told me a lie, I do him no wrong if I lie to him in return, but I violate the right of mankind; for I have acted contrary to the condition, and the means, under which a society of men can come about, and thus contrary to the right of humanity. (Kant 1997 [c.1784]: 200-201, 203)

This destruction of a fellowship rooted in the communication of attitudes (Kant), corruption of testimony (al-Qayyim), and destruction of the means, 'our word', through which we have ties upon one another (Montaigne), are all variants of the thought that lying is distinctive in being objectionable because of its abuse of a method, namely, verbal testimony, and linguistic exchange more generally. ${ }^{18}$

The thinking behind this tradition can be understood in terms of the quibble I had with Saul's argument. Acquiring someone else's bike is, it seems, distinctively wrong if the method used is stealing rather than, say, persuading them to give it to you. The intended outcome is the same: a transfer of effective ownership. What distinguishes stealing from other methods is the harm it does to the social practice of ownership, since that practice presupposes respect for a norm: property transfer requires permission. Likewise, on the tradition under consideration, causing another to have false beliefs is distinctively wrong when the method used is lying rather than non-communicative deception (e.g. leaving a lead-filled football in a park). What

\footnotetext{
16 Ibn al-Qayyim (2002), 1:95. I am grateful to Sohail Hanif for advice on the translation.

17 Translated from his essay on liars (1907 [1595]). I have followed others in giving 'la parole' its idiomatic sense: 'our word' rather than 'speech'.

18 Bok (1978: 26) and Fried (1978: 68) also sit within this tradition. Augustine is less explicit but circles around the idea of lying as a corruption of God's gift (e.g. 2002 [c.395]: §42, p. 108).
} 
distinguishes lying from these other methods is the harm it does to a social practice, the very social practice it exploits in fact: communication by linguistic exchange. Exactly when a choice of method does or does not matter is an interesting question that is outside the scope of this paper, but on the evidence of these two examples it seems to have something to do with the existence of a background social practice such as ownership or linguistic exchange. In any case, the longstanding tradition sketched above does suggest that we should wary of following Saul in assuming that deception by lying is morally equivalent to deception by any other means.

Before turning to Shiffrin's development of this case for the 'distinctive wrong of the lie' (2014: 21-26), it will be instructive to raise a couple of objections to the view as thus far presented. First, the claim that linguistic exchange is harmed by lying seems simplistic. It has the paradoxical implication that a good liar, one who is never exposed and so who does not undermine ordinary linguistic exchange, is less objectionable than a bad liar. Some sensitivity to this point is evident in the quotation from al-Qayyim. He talks, not of damage or undermining, but of 'corruption' and of contrariness-to-function. I propose we set this first worry aside. It has the same structure as problems that crop up whenever some background system of moral norms is robust enough to withstand covert violations. Whatever general solution we adopt_Kant's universalizability requirement, say (cf. Shiffrin 2014: 23) —is likely to work here if it works elsewhere. As a nod to this point I will henceforth use the word 'abuse' instead of 'harm'.

A second objection is more significant. If lying is an abuse of linguistic exchange, then so too-arguably - is false insinuation, misleading allusion, etc. So if being an abuse is what makes lying wrong, it does not make it distinctively wrong. On the face of it, then, Saul's argument survives: being an abuse of linguistic exchange does not make lying wrong in any respect that distinguishes it from plenty of other instances of verbal deception. This second objection ultimately succeeds in showing that lying is not distinctively wrong, but Shiffrin offers the ingredients for a vigorous response.

Shiffrin allows that lying often involves deception, and so can be wrong for the same reason that deception in general can be wrong; but she holds that there is more to lying's potential wrongness than its being deceptive. Echoing Kant's talk of a 'fellowship', she holds that 'moral agency is a cooperative matter that depends on the reliable channels of communication' and that 'the stricture on lying plays [a role] in maintaining reliable channels of communication between moral agents'. This, she maintains, serves to distinguish 'the wrong of the lie from the wrong involved in deception (when it is wrong)' (2014: 2-3, cf. 9-26). Thus far, her version of the approach is susceptible to the second objection: a stricture on falsely insinuating could be justified on parallel grounds, in so far as falsely insinuating also 'taints' testimony (2014: 23). The ingredients for a reply to the second objection are to be found in her further claim that to perform its vital moral function, linguistic exchange must have two qualities: precision and authority (2014: 10, 23). Both qualities depend on the explicit use of words with their more-or-less exact meaning, and the loss of either quality has regrettable consequences. For precision, consider how easy it is easy for someone to wriggle out of a vaguely worded promise. For authority, consider an expression of preferences or experiences by someone in a socially 
subordinated position, where failure to regard their actual words as authoritative permits the imposition of an interpretation on their utterances that poorly reflects their true state of mind.

Shiffrin's claim here, that precision and authority are important in many morally charged contexts, is convincing. So too is her suggestion that explicitly uttered and independently meaningful words play a crucial role in sustaining these two qualities. She does not, however, supply a clear reason for inferring from this crucial role to the need for a special prohibition on lying as opposed to, say, deceiving someone by knowingly communicating a falsehood without actually lying. I will consider and reject two possible grounds for drawing such an inference. ${ }^{19}$

One turns on the thought that precise meanings are sustained by linguistic conventions, conventions that are undermined by lying. According to David Lewis (1975), for example, a linguistic community's words mean what they do because of a convention, reflected in the beliefs and behaviour of that community, to utter sentences truthfully and interpret them trustingly in accordance with that meaning. Lying, we might suppose, undermines this convention, with the result that words lose their precise meanings. Whether or not this is what Shiffrin has in mind, it does not give her what she needs. Quite apart from whether Lewis has a credible account of word meaning (pace Laurence 1996), lies do not undermine whatever conventions sustain linguistic precision. Indeed, they trade on this very precision. The threat posed by lying is not to precision so much as to speaker trustworthiness, a worry that attaches to any instance of duplicitous communication. If anything, precision is threatened more by allusive and evasive discourse than it is by blatant lying.

A more plausible grounding for Shiffrin's inference turns on a well-established feature of non-literal speech: the appearance of an unstated meaning can be cancelled (Grice 1989 [1967]: 39, 44). This cancellability makes false insinuations easier to deny than lies. Recall example (6b), and suppose the candidate's true calibre has been discovered. The referee could retrospectively insist: 'I didn't mean to be damning her with faint praise: punctuality and the like are important strengths in a modern academic.' That is, he can falsely deny that his utterance meant what others took it to mean. Denial and cancellation are not the same thing here: to cancel is to immediately remove an apparent insinuation whereas to deny is to later insist, perhaps falsely, that there was no insinuation. In practice, however, they are co-possible, meaning that false insinuations can easily acquire (to borrow the legal phrase) plausible deniability. This manoeuvre is unavailable for outright lies, the content of which is not cancellable in the same way. Their content is tied to the words used, giving them the qualities of precision and authority that Shiffrin prizes. For this reason, we might infer that there is something especially brazen, and therefore distinctively wrong, about lying.

\footnotetext{
19 Shiffrin treats lying as assertion-involving and in a footnote says that 'for convenience' she will treat assertion as involving explicit language. She 'brackets' the possibility that one may assert, and so lie, without being explicit—by uttering 'Ouch!' when not in pain, say (2014: 12n). She may therefore be more accepting of the claims made here than I suggest in the main text. Either way, her actual arguments - and in particular her emphasis on the precision and authority made possible by explicitness-are instructive in the present context.
} 
To see why this second attempt to underwrite Shiffrin's inference also fails, consider an analogy involving two shoplifters, Techy and Actor. Techy has found a way of disabling the security tag that would trigger an alarm at the store's exit. Actor simply puts items carelessly in his bag and hopes not to be stopped. Whenever he is, he claims to have made an innocent error. Techy, if stopped, has a visibly interfered-with tag in her bag whereas Actor has plausible deniability. Actor's actions are nonetheless every bit as wrong as Techy's and vice versa. Liability to being found out does not alter the wrongness of the act itself. Condemnation will in practice be harsher when a target has been caught red-handed, but only because of an absence of doubt. Likewise, the fact that liars can be caught red-handed whereas false insinuator can retrospectively 'cancel' (or more accurately, falsely deny) the insinuation should not mean we treat these acts as morally distinct, other things equal. The mechanics of how a wrong act is spotted is distinct from the nature of the wrongness itself (a point also made by Adler 1997: 446).

In sum, Shiffrin has failed to establish that lying is a significant moral category, distinct from instances of duplicitous speech that trade on insinuation and the like. On the other hand, she and others in the same tradition have shown that there is more to the wrongness of lying than deliberate deception. Lying can also be wrong because it abuses the social practice of communicating by linguistic exchange. Her only mistake is to assume that this holds only of lying. The moral kind she brings into relief occupies a wider conceptual space. This is the space I propose we fill with the notion of dishonesty. Dishonest acts will include lies, though not only lies; but the notion will not be so broad as to include all acts of attempted verbal deception, since not all verbal deception incorporates an abuse of linguistic exchange. That, at least, will be the claim in Sect. 2, the function of which is to properly elucidate this new notion.

\section{Dishonesty}

The arguments of Sect. 1 suggest that the lying/misleading debate is misconceived because the real moral interest lies somewhere other than at the saying/not-saying boundary. They also indicate that we should turn our attention instead to a moral category with the following attributes: it is broader than lying, narrower than attempting to deceive, and instances of it are wrong for the reasons Shiffrin, etc., mistakenly treat as characteristic of lying (namely, that it somehow abuses the social practice of communication by linguistic exchange). We already have a label-in-waiting for this category: 'dishonesty'. What we still lack are a definition and some assurance that, once defined, dishonesty is a coherent notion.

\subsection{A Definition of Dishonesty}

While dishonesty is distinct from lying, it is easy to see how our earlier definition of lying can be converted into a definition of dishonesty:

Dishonesty $=$ expressing that $p$ when one knows $p$ to be untrue. 
Points made earlier (about using 'knows' rather than 'believes', and not requiring an intention to deceive the audience into believing that $p$ ) carry over. The difference lies only in the use of 'expressing' in place of the more demanding 'saying'.

While dishonesty is more inclusive than lying, it is not equivalent to seeking to cause someone to believe that $p$ when one knows $p$ to be untrue. This is what creates the space for there being something distinctively wrong with dishonest acts (including cases of lying) other than their being attempts to deceive. While it is (usually) wrong to cause someone to be deceived, to knowingly express a falsehood is to do something above and beyond that: it is to abuse the social practice of communicating by linguistic exchange. In other words, what Shiffrin describes as the distinctive wrong of the lie can be resurrected as the distinctive wrong of dishonesty.

This proposal may be felt to trade on an absurdly fine distinction, or even on an imaginary one. Once expressing something is cut loose from saying it, what is the difference supposed to be between expressing a falsehood and merely seeking to cause one's audience to believe a falsehood through the performance of a verbal act? Showing that the distinction has practical import is the burden of Sect. 3, but to clear the ground I will first address scepticism over the distinction's very existence. To begin, we need a better sense of what is involved in 'expressing that p'.

\subsection{What is it to 'Express that p'?}

What sets expressive acts apart is their meaningfulness. Consider three acts by $x$, each intended to deceive $y$ into believing that there are foxes in the neighbourhood:

Act A: $\quad x$ utters 'We have foxes. I saw them last night.'

Act B: $\quad x$ utters 'I never realised we have foxes.' [cf. (1b)]

Act C: $\quad x$ pulls $y$ 's rubbish from $y$ 's bin in the night and scatters it over $y$ 's lawn

Section 1 was focused on the contrast between A (a lie) and the others; now our interest is in the contrast between $\mathrm{C}$ and the others. $\mathrm{A}$ and $\mathrm{B}$ are expressive acts while $\mathrm{C}$ is not. $\mathrm{C}$ is not an attempt at meaningful communication.

A qualification to this is in order: there is $a$ sense of 'meaning' in which rubbish scattered across the lawn is meaningful. We can imagine $y$ muttering, 'Hmmm, that must mean we have foxes'. But this is not the kind of meaning that underpins human communication. It is, rather, what Grice calls 'natural meaning' (1957: 378). Natural meaning has a giveaway feature: if something naturally means that $p$, then $p$ must be true. So while $y$ in scenario $\mathrm{C}$ may think that the messy lawn (naturally) means that there are foxes in the area, it does not actually (naturally) mean this. At most, the messy lawn appears to (naturally) mean that there are foxes. The kind of meaning that is distinctive of communication and manifest in scenarios A and B lacks this dependency on the truth of what is meant. In them, $x$ 's acts carry the meanings they do despite the absence of foxes. Where it is useful to do so, I will use 'expressive meaning' to pick out the kind of meaning that is manifest in $\mathrm{A}$ and $\mathrm{B}$ but not C. (This is why I have chosen 'expresses that' over 'means that' in the definition of dishonesty.) 
The history of attempts to define the kind of meaning that makes something an expressive act begins with Grice's own effort. The following is based on his definition of what he calls 'non-natural meaning' (1957: 383-384):

An act expresses that $p$ iff it is intended to induce in an audience the belief that $p$, and is intended to do so through the audience's recognition of this first intention.

Don Fallis adopts a Gricean formulation in his account of what is in effect the same boundary as the one I am trying to draw here, between acts that merely cause false belief, and those that attempt to communicate a falsehood - a line we both take to be morally significant. Unfortunately the Gricean formulation has long been known to be inadequate, making it useless for our purposes. ${ }^{20}$ We can see this with a simple example. Suppose a crime suspect utters "I stole the diamonds" to a police detective. She did in fact steal the diamonds, but secretly wants the detective to infer from the haste of her confession that she is a patsy rather than the real thief. While intuition tells us that the suspect is expressing (and indeed saying) that she stole the diamonds, the Gricean condition is not met. Of course, one might try to fix this with a tweak, but more examples call for more tweaks and a long trail of attempts along these lines petered out in the last century. ${ }^{21}$

We do better, I suggest, if we acknowledge a distinction at the heart of speech act theory, between the typical downstream effects a communicative act-its perlocutionary effects - and the expressive act as such, which is illocutionary in nature. An illocutionary act, as I am using the term, is one that requires, for its performance,

\footnotetext{
${ }^{20}$ Fallis 2010: 14-17. My main difference with Fallis relates to his reliance on Grice's formulation (see main text). In addition, his stated goal is to define 'lying' (or 'broad descriptive lying') rather than 'dishonesty'. While this could be seen as nothing more than semantic choice, it is symptomatic of a difference in approach. He is interested in concept analysis (Fallis 2009: 30-33; Fallis 2010: 5) whereas I am concerned with identifying morally significant boundaries, irrespective of whether these align with those of our current concepts (pace Fallis 2009: 37). The same goes for Meibauer's (2014: 113-123) notion of 'extended lying', which would include implicating a known falsehood. Despite strong affinities between extended lying and the notion I am after (terminological discrepancy aside), Meibauer is interested primarily in an account of 'lying' that reflects 'how language works', disavowing any serious attempt to argue for the moral significance of extended lying (pp. 2, 14-15). Moreover, in lieu of an alternative to Grice's flawed definition of non-natural or speaker's meaning (such as the one I give shortly in the main text), Meibauer relies on the informal notion of 'presenting' a proposition as true (e.g. p. 121), which he does not properly unpack. A few others treat the (in my terms) dishonest/deceptive boundary as significant but likewise fail to supply a credible account of where it lies. Adler's account, like Fallis's, rests on a problematically Gricean approach to non-natural meaning (Adler 1997: 444-445). Simpson (1992) claims that 'lying involves false presentation of belief, plus acting on the intention that the one lied to recognize that the liar intends them to take this as a presentation of belief' (p. 634). His first conjunct comes close to my definition of 'dishonesty', while his second can be read (charitably), not as a further condition, but as a move towards elucidating 'presentation of belief' - somewhat in the spirit of my elucidation of 'expressing that p' in the main text.

${ }^{21}$ See Schiffer $(1972,1987$, ch.1) for a concerted effort. The jewellery thief example, comparable to Augustine's 'bandit' cases (2002 [c.395]: §4, pp. 56-59), is a problem for his view. What makes the suggestion below 'non-Gricean' is recognition that an intention to shape an audience's beliefs-Grice's first condition-is incidental to expressive meaning.
} 
the intention of audience uptake. ${ }^{22}$ Asking the time is an illocutionary act, for example, since one cannot ask the time without the intention of being recognized as having asked the time. One usually asks the time not simply in order to be recognized as having asked the time, of course, but in order to learn the time. This latter is among the intended perlocutionary effects. But neither production of this perlocutionary effect, nor an intention to produce it, is necessary or sufficient for asking the time. The diamond-thief example trades on just this dissociability: bringing about a change in belief is merely a typical perlocutionary effect of assertion.

We do not need the entire edifice of speech act theory here. All we need is to equate expressive acts with acts that are illocutionary in the sense just given: they have a certain kind of willed openness-of-intention on the part of the agent. More precisely, let us say that an individual act is expressive if it falls under some type $\varnothing$ of which the following biconditional schema holds:

\section{The openness-of-intention biconditional}

One $\emptyset_{\mathrm{s}}$ if and only if one acts with the intention of being recognized as Øing.

Substitutions for ' $\varnothing$ ' that satisfy this biconditional include ask the time, drop a hint, promise, invite, and apologise. One cannot do any of these things without intending to be recognized as having done so by a target audience. ${ }^{23}$ Substitutions for $\varnothing$ that fail to satisfy the schema include kick and cause a delay. Most of the things we do, in fact, are doable without any intention to be recognized as having done them, and vice versa; expressive acts are highly unusual in this respect. (An instance of kicking can be expressive, of course. It might serve as a statement of power, for example. But in that case, what makes the kicking expressive is its falling under this further description, which does satisfy the biconditional. Unlike being a kick, being a statement of power requires the agent to intend that the act be recognized as such by some audience.)

This is enough to capture how Act $\mathrm{C}$ differs from Acts A and B. Replacing $\varnothing$ with cause someone to believe there are foxes in the area in the openness-of-intention biconditional does not yield a true instance; and since no other description of $\mathrm{C}$ fares any better, $\mathrm{C}$ fails to express anything (so is merely deceptive, not dishonest). Act $\mathrm{A}$ is an assertion, however, and Act $\mathrm{B}$ an intimation. Both therefore fall under descriptions that satisfy the biconditional and so both are expressive acts (and so dishonest).

The openness-of-intention biconditional tells us what it is for an act to be expressive but does not tell us how expressive act-types differ from one other. To give an account of promising, for example, we would need to provide supplementary

\footnotetext{
22 The suggestion made here draws on Donald Davidson's notion of a passing theory (1986), and on Searle (1969, esp. p. 46).

23 Does the 'if' direction of the claim allow - absurdly - that one can ask the time by juggling pineapples while intending to be interpreted as asking the time? Such apparent counterexamples can be dealt with by noticing that an act of pineapple juggling is not something one could intend to be so interpreted. Intention formation requires some expectation of success. If one had an internally reasonable (albeit bizarre) expectation of success and so formed and acted on the intention, it is tolerable to describe this as asking the time using a wildly misguided vehicle of expression and no real chance of audience uptake.
} 
conditions that distinguish it from asking, saying, etc. This kind of classificatory task is undertaken by speech-act theorists at a level of detail that goes well beyond current requirements. ${ }^{24}$ All we need is a supplementary condition that captures, specifically, the expressive acts in which an agent expresses that something is the case. The obvious suggestion to make is simply that they have truth conditions. Expressive acts without truth conditions include asking for the time, telling a story, or painting an imaginary scene. Once we set those aside, the meaning of 'express that $p$ ' in the definition of dishonesty comes into view. Saying that $p$ is a paradigmatic way of expressing that $p$, but others include intimating that $p$, using verbal irony to suggest that $p$ (see (3b)), or even depicting that $p$ so long as the picture is offered as a veridical representation. ${ }^{25}$

\subsection{The Difference in Extension Between Dishonesty and Merely Seeking to Deceive}

We can see now why dishonesty, even of the non-lying sort, comes apart in its extension from simply attempting to deceive. An act of attempted deception will count as a case of dishonesty only if it is also the expression of the relevant falsehood. This requires the presence of communicative intentions of the kind just characterized. We even have an illustration of the contrast: while Acts A and B are dishonest attempts to mislead, Act $\mathrm{C}$ is an attempt to mislead but is not dishonest. Another example can be extracted from Kant's luggage example, but because (5b) is under-described we must first distinguish two variants. If the deception is meant to come about simply through the luggage being visible to onlookers, there is no dishonesty because there is no communicative intention, only an intention to deceive. If instead we envisage him looking from the neighbours to the bags and back to the neighbours, eyes wide and eyebrows raised, overtly inviting his neighbours to draw the obvious conclusion, then he has the communicative intentions that render him dishonest.

A potentially concerning feature of these two examples of non-dishonest deception is that they are non-verbal. We do also have a verbal case of non-dishonest deception: the diamond thief's misleading but honest confession; but this could be dismissed as a special case given the poverty of trust between the criminal and the detective. Consider, then, the case of $\mathrm{P}$, who has been invited to a party. Q wants $\mathrm{P}$ to decline. $\mathrm{P}$ is known for holding the idiosyncratic but unshakeable view that all philosophers are obnoxious. Q says, truthfully, that the party's host is a charming philosopher. Q's intention in saying this is to cause P to believe, falsely, that the host is obnoxious, and so to stay away. Despite this intention to deceive, Q has not expressed the opinion that the host is obnoxious, so this is not a dishonest act. It would be if Q adopted a certain tone of voice, with audible shudder-quotes around the phrase "charming philosopher", but we can suppose she does no such thing. She

\footnotetext{
24 The foundations for this work are Searle (1969: 66-67), Searle and Vanderveken (1985).

25 The conditions under which what is intimated, etc., is true are not tied compositionally to the expressions used. To insist on compositionality would make 'expressing that' too close to 'saying that' and the whole point is to achieve a broader notion.
} 
just leaves it to $\mathrm{P}$ to draw the false conclusion under his own steam, relying on a belief that both realise is his alone. It would be strange to insist that $\mathrm{Q}$ has expressed the opinion that the host is obnoxious when she explicitly says, and believes, and is taken by $\mathrm{P}$ to believe, that the host is charming. ${ }^{26}$

\subsection{How the Wrongness of Dishonesty Differs from the Wrongness of Seeking to Deceive}

Establishing that dishonesty is extensionally distinct from merely seeking to deceive is not the same as establishing that the wrongness of dishonesty (when it is wrong) is distinct from the wrongness of involved in seeking to deceive (ditto). The examples given so far may give cause for concern on this point. Altering a person's environment so as to deceive them (as with Act C) seems, if anything, worse than lying to or being otherwise dishonest with them (as with Acts A and B). At least if you lie or falsely insinuate, others can isolate your utterances as the untrustworthy source. When you start planting misleading clues in a person's environment, you do not poison a single well, you poison the aquifer. My claim, however, is not that dishonesty is worse than mere attempted deception. Sometimes it will be worse, sometimes it will be comparatively trivial. The claim, rather, is just that dishonesty's wrongness is distinctive. Dishonesty is objectionable because it uses a morally problematic method, the method of expressing a known falsehood, using communicative intentions of the sort captured in the openness-of-intention biconditional. It is an abuse of communication.

Is this method so special that it warrants talk of abuse? Recalling Saul's discussion of the moral irrelevance of method, we would not put much weight on the contrast between murdering by truncheon and murdering by strangulation, or deceiving by perceptual illusion and deceiving by planting objects in the environment. Why pick on deception that exploits the expression of known falsehoods? I suggested in Sect. 1.3 that a choice between two methods is morally significant if just one of the methods violates a norm without which a morally important social practice would be impossible. Theft is an objectionable method for transferring effective ownership because it violates a norm without which the social practice of ownership would be impossible, namely, the norm that property transfer requires permission. At this point we can draw on Shiffrin's (and Kant's, etc.) insistence on the moral importance of communication by linguistic exchange. Knowingly expressing a falsehood involves the abuse of communication, the social practice whereby we openly display communicative intentions to our fellow beings. This practice is vital to ethical participation in a shared social domain and it is only viable because these displays are taken to be governed by a norm of honesty. I differ from Shiffrin only in taking the relevant social practice to include expressive meaning as well as the literal use of language. For reasons set out in Sects. 1.2 and 1.3, literal assertion is too restrictive a description of the social practice being abused.

\footnotetext{
${ }^{26}$ Saul's Careful Victim/Reckless Victim analogy (2012b: 83), I am therefore suggesting, glosses over distinctions that apply in the linguistic case: sometimes the audience $i s$ responsible for its own deception.
} 
Talk of shared social domains and fellowship could give the false impression that the obligation to avoid dishonesty is just part of parcel of some global obligation to be nice to each other. Yet it is when human interactions are somewhat confrontational that the true value of honesty comes to light. Even where people are entitled to act with some degree of partiality - to look out for their own interests in their dealings with someone who is clearly looking out for theirs-they are obliged to do so within constraints. One of those constraints is the obligation not to abuse the system of communication by linguistic exchange. Shiffrin herself gives the example of respect for the convention of the white flag during war (2014: 23); more familiar examples are the obligation to avoid dishonesty in, say, a courtroom, or during tense domestic negotiations (cf. Grice 1989 [1967]: 29-30), when feelings between opposing parties are non-benign and respect for the honesty requirement acts as a crucial moral minimum.

I said at the start of the paper that the label 'dishonesty' is not essential to the thesis defended here. This remains the case, but one might nonetheless object even to this stipulative use. Theft, for example, is sometimes described as dishonest, and I suggested the longer phrase, 'communicative dishonesty', so as to avoid being distracted by such worries. But in fact the example of 'dishonest' theft supports the choice of label, for notice that we do not call all instances of theft dishonest with the same willingness. If a servant steals the silverware, we call it dishonest; if an outof-town burglar does so, the description feels less apt. The difference seems to be that the servant will in the past have falsely represented herself as trustworthy to the silverware's owner - an expressive act—whereas the burglar will not have done so. In the end, 'dishonest' is as flexible a word as 'lie', and any definition must always be seen as somewhat stipulative. For example, we also use 'dishonest' to describe a background vice of character that both the burglar and the servant are likely to possess. Still, our apparent willingness to apply 'dishonest' only to acts involving some element of misrepresentation speaks in favour of this choice of label.

\section{Applications}

The examples in the first two sections were often artificial, designed around the goals of revealing where the standard existing debate has gone wrong and pinning down a new moral category. This final section illustrates how the notion of dishonesty presented in Sect. 2 can be put to work in analysing the ethics of communication in three settings: political journalism, law, and personal conversation. The illustrations are of necessity quite brief, designed only to show how new avenues of enquiry open up when we shift our attention from the lying/not-lying boundary to the dishonest/not-dishonest boundary.

\subsection{Politics and Political Journalism}

Nuanced speech is a requirement of political power but careful inflections can easily slide into what I am calling dishonesty without necessarily involving a lie. How 
easy it is for a politician to avoid dishonesty will depend in part on the coherence and appeal of their politics. For just this reason, political journalists have a special obligation to keep politicians honest. Here I will briefly consider a single case of populist dishonesty, along with the journalistic reaction to it, using the apparatus of Sect. 2.

In 2017, US Senator Kirsten Gillibrand had been pressing President Donald Trump on allegations of serious sexual misconduct. He responded:

Lightweight Senator Kirsten Gillibrand ... would come to my office "begging" for campaign contributions not so long ago (and would do anything for them), is now in the ring fighting against Trump. ${ }^{27}$

The communicative intention here - a suggestion that Gillibrand was willing to perform sexual favours in return for financial support-is evident from the otherwise redundant phrase 'coming to my office', the desperation implied by 'begging', and Trump's conspicuous failure to spell out what her offer was despite asserting that she was willing to 'do anything'. Still, he did not say it, giving him deniability. He left the denial to his spokesperson at a press briefing:

Journalist 1: What is he alleging would happen behind closed doors with her?

Spokesperson: He's not alleging anything. He's talking about the way that our system functions as it is.

Journalist 2: [Is Gillibrand] owed an apology for the misunderstanding of the president's tweet this morning, because many ... say it's about sexual innuendos

Spokesperson: I think only if your mind is in the gutter would you have read it that way ${ }^{\mathrm{a}}$

${ }^{a}$ The full exchange is at http://www.youtube.com/watch?v=iLCpQ58TL4E\&feature=youtu.be, 21'23"23'07" (retrieved 31.07.19)

There are two related lessons here for political journalists. The first: start caring less about lying and more about dishonesty. The second is a corollary of that: learn to understand, identify, and call out dishonesty that falls short of outright lying. The phenomenon is common and those with a professional responsibility for confronting it need to be skilled at doing so. Rather than simply teeing up an easy denial, for example (Journalist 1), or readily accepting that denial (Journalist 2), they might ask a question that sets out the evidence for this being the insinuation, and better anticipates the false denial in a way that makes it embarrassing or even implausible when it comes (e.g. 'The president looks like he was phrasing it this way merely so he could deny it later. Are you going to do the denying for him now?'). Whether any strategy would have been effective in the hustle of this particular press briefing is harder to say, but arming journalists with a better conceptual and tactical repertoire would at least make political dishonesty a less tempting option.

$\overline{27}$ http://twitter.com/realDonaldTrump/status/940567812053053441, $\quad$ 05h03, December 172017 (retrieved 31.07.19). 


\subsection{Law}

Honesty is a foundational notion in law. How it is deployed varies according to legal tradition, jurisdiction, area of law, and accidental features of particular statutes and judgements. Here, I offer no more than a flavour of how the definition in Sect. 2 might help in the legal domain.

The seven 'Nolan Principles' of public life have no statutory power in themselves but, as was intended, they have been adapted then adopted by many regulatory bodies that do, in the UK where they were developed, and beyond. Each of the principles is given a gloss. For 'Honesty' the gloss is appealingly direct-'Holders of public office should be truthful ${ }^{28}$ _ but a moment's reflection leads us to ask what truthfulness amounts to in this context. The definition of dishonesty in Sect. 2 offers a way of capturing what seems to be the spirit of the principle: be truthful in what one expresses, not merely in what one says, where 'expresses' is unpacked in terms of communicative intentions.

In many legal contexts, words like 'dishonesty' and 'misleading' function as basic legislative building blocks, their interpretation left to the reasonable jury member or judge with an occasional steer from case law (e.g. the definition in the UK's Fraud Act 2006 of 'fraud by false representation' ${ }^{29}$ ). Where this is so, the account given in Sect. 2 represents, at the very least, a potential default understanding of dishonesty.

The definition could also have a use in the law of perjury. An important ruling, Bronston v United States (1973), deals with responsibility for literally true but misleading witness statements. The case turned on this exchange in a lower court:

Q. 'Do you have any bank accounts in Swiss banks, Mr Bronston?'

A. 'No, sir.'

Q. 'Have you ever?'

A. 'The company had an account there for about 6 months, in Zurich.'

Mr Bronston here omits to mention that he once had a personal account with a Swiss bank, an omission that is not picked up. As we have seen, some literally true but deliberately misleading statements are dishonest while others are not. It is unclear which category Mr Bronston's second reply falls under since his communicative intentions are not evident beyond his choice of words. The 1973 ruling, in any case, renders this difference moot. The opinion bundles together all deliberately-misleading-but-literally-true statements, whether or not they are also dishonest (in my sense). It claims, in effect, that there is no obligation on the part of the witness to be honest over and above the obligation to avoid explicit lies. Responsibility rests entirely with counsel to spot all forms of misleading statement so long as they are

\footnotetext{
28 CSPL (1995: 14). Updated versions are maintained at http://www.gov.uk/government/publications/ the-7-principles-of-public-life (retrieved 31.07.19).

29 The Act is at http://www.legislation.gov.uk/ukpga/2006/35/section/2 (retrieved 31.07.19). Case law demands use of the so-called Ghosh test: 'dishonest by the ordinary standards of reasonable and honest people'. See Summers (2008).
} 
literally truthful-i.e. even if they are dishonest. This is a peculiar concession. We can grant that a lawyer's ability to spot dishonesty alongside all other forms of misleading testimony is a core professional skill. We can also grant that, in the absence of literal falsehoods, proving dishonesty will often be hard since its existence turns on communicative intentions. But neither consideration supplies us with a clear reason to lift responsibility for dishonesty from a witness. A more coherent stance would be to require honest testimony (notwithstanding the fact that some violations will be hard to prove ${ }^{30}$ ) without requiring that testimony never be intended to cause or sustain false beliefs (which would be too stringent).

\subsection{Personal Conversation}

The analysis of dishonesty in Sect. 2 can help us break down some of the moral complexity of ordinary conversational dynamics. Here I will touch on just two issues: the moral status of tactful dishonesty that falls short of lying, and what to count as part of an utterance's expressive meaning (and hence what to count as honest or dishonest).

Jonathan Adler holds that false but tactful hinting is less objectionable than lying. He gives the imaginary but realistic example of Larry asking Mark 'Where's Laura?' when, unbeknownst to him, Mark and Laura have just separated. To avoid social discomfort, Mark answers, 'Oh, she is away on business', which indeed she is. In Adler's view, 'the opportunity to deceive smooths over social frictions without the naked transgression of a lie' (1997: 447). False but tactful hinting, Adler suggests, is a welcome safety valve for the pressure generated in social situations when we would otherwise have to choose between lying and revealing a truth we (perhaps quite reasonably) do not wish to reveal.

Adler's argument trades on a failure to distinguish dishonesty that falls short of a lie from non-dishonest deception. In his example, it is unclear whether Mark has been dishonest. That depends on how he took Larry's question. If he took Larry's tone to contain an implicit 'Oh no! Is everything okay?' then Mark's response is dishonest since it in turn would contain an implicit hint that yes, everything is okay. ${ }^{31}$ Call that scenario Adler 1. In Adler 2, Mark is just giving a straight answer to what he takes to be a straight question. While wary of revealing the uncomfortable truth, he is neither suggesting nor denying that everything is okay. He is being honest, even though he wants Larry to assume, falsely, that everything is okay between Mark and Laura. We must therefore say different things about each case in a way that Adler does not seem to appreciate. In Adler 2, there is no dishonesty, no tactful hinting of a falsehood, only a reasonable willingness to cause or at least to sustain a false belief. In Adler 1, there is dishonesty, but any intuition that this is less of a transgression than a tactful lie arguably depends on conflating Adler 1 and Adler 2.

\footnotetext{
30 Or not so hard if Adler is right about the effectiveness of 'the all-purpose end question: To the best of your knowledge, are there any other relevant facts?' (1997: 440).

31 In Grice (1989 [1967]), the maxim of quantity would do the work; other frameworks would offer different accounts of the mechanism.
} 
The second issue is what to include within the expressive meaning of an utterance. There is a complication here. Earlier I contrasted natural meaning with expressive meaning and set it aside, but in fact what we express (without saying) frequently trades on the real or apparent natural meaning of what we say. Consider a variant of the 'obnoxious philosopher' case. A new colleague of J and K is hosting a party. K wants J to go, so tells J, truthfully, that the host is 'extremely wealthy'. The clear subtext is that it will be a sumptuous event, which both of them know will appeal to J. K's communicative act trades on the apparent natural-meaning relation (i):

(i) Extremely wealthy people throw sumptuous parties.

But there are many other apparent natural-meaning relations in the same vicinity, e.g.:

(ii) Extremely wealthy people have diversified investment portfolios.

Does (ii) also contribute to what K expresses? If so, and if, unusually, the host is known by $\mathrm{K}$ (but not J) to have all his wealth invested in a single company, K's utterance would count as dishonest. This threatens to undermine the utility of the present notion of dishonesty. Either dishonesty is impossible to avoid or else its scope is too indeterminate to be useful.

We need a way of demarcating, within the class of apparent natural-meaning relations, just those that contribute to what a person expresses. Here we must fall back on a silent assumption I have been making throughout: robust realism about mental states, particularly intentions, and still more particularly communicative intentions. What makes it the case that (i), unlike (ii), is part of the expressive content of K's utterance is simply that $\mathrm{K}$ had the communicative intentions she did. Specifically, she intended to be interpreted by $\mathbf{J}$ as suggesting that the party would be sumptuous-where 'suggest' satisfies the openness-of-intention biconditional of Sect. 2whereas she had no parallel intention in respect of wealth portfolios. All manner of circumstances will have been necessary in practice for $\mathrm{K}$ to have had the communicative intention she did. Most obviously, she must have expected audience uptake of the communicative intention. With no prior expectation that $\mathbf{J}$ will interpret her utterance as bearing on the host's investment strategies, $\mathrm{K}$ would have been unable to form the intention that $\mathbf{J}$ so interpret her. Intention formation requires some expectation of success, after all. The expectation of uptake itself has certain preconditions, such as conversational salience, mutual knowledge, etc. Perhaps $\mathrm{K}$ and J have discussed J's weakness for sumptuous parties recently. The exact psychological mechanisms can, for our purposes, be left opaque. But it is not unreasonable to suppose that there is a fact of the matter as to which communicative intentions a person is acting on when they speak, and that these facts of the matter can underpin a difference between dishonesty and mere intention to cause false belief. 


\section{Conclusion}

The traditional lying/misleading debate is fixated on whether saying something false, as opposed to merely insinuating or hinting at it, matters. The important moral category in this area, dishonesty, pivots on an entirely different distinction, the one between what has or has not been expressed. Lying, I have argued, is at most a morally uninteresting subcategory of dishonesty, and the traditional debate distracts us from more interesting questions.

To reach this conclusion I examined two representative positions on opposing sides in the traditional debate, combining what is right in each while dropping what is wrong. Saul is right in holding that the lying/not-lying boundary is morally insignificant, but wrong in assuming that there is no morally significant boundary in the same neighbourhood, and so wrong in assuming that lying is therefore of a kind, morally speaking, with all attempts to mislead. Shiffrin is right about the moral nature of this other boundary-it is the difference between acts that do abuse linguistic exchange and those that do not-but she misidentifies it as the boundary between lying and merely attempting to deceive without lying.

The hardest aspect of the shift of focus I am recommending here involves specifying what it is to express (i.e. to try to communicate) a known falsehood. I argued that this is not the same as trying to cause someone to believe the falsehood. The ingredient vital to an act's expressing something, I have suggested, is its being produced with a communicative intention, so that audience uptake is part of the success condition. While this is a complex idea in the abstract, I ended by trying to show how the resulting notion might nevertheless have application in real-world settings.

Acknowledgements For many helpful comments on earlier versions I am grateful to participants at the Sixth Workshop on Language Cognition \& Context workshop in Montevideo (and in particular for commentaries from Patricia Brunsteins and Tim Kenyon); members of the Ethics Forum in the University of East Anglia; my Open University philosophy colleagues; and referees for this journal.

Open Access This article is distributed under the terms of the Creative Commons Attribution 4.0 International License (http://creativecommons.org/licenses/by/4.0/), which permits unrestricted use, distribution, and reproduction in any medium, provided you give appropriate credit to the original author(s) and the source, provide a link to the Creative Commons license, and indicate if changes were made.

\section{References}

Adler, Jonathan E. 1997. Lying, deceiving, or falsely implicating. Journal of Philosophy 94(9): 435-452.

al-Qayyim, Ibn. 2002. I ' lām al-muwaqqi '̇̀n 'an Rabb al- 'Ảlamīn. Mashhūr Hasan Āl Salmān, ed. Riyadh: Dār Ibn al-Jawzī.

Augustine. 2002 [c.395]. Lying. In Treatises on various subjects, ed. R. J. Deferrari; Mary Sarah Muldowney, trans. New York: Catholic University of America Press.

Bach, Kent. 1994. Conversational impliciture. Mind and Language. 9(2): 124-161.

Bok, Sissela. 1978. Lying: moral choice in public and private life. Hassocks: Harvester Press.

Bronston v United States. 1973. 409 U.S. 352, 93 S. Ct. 595, 34 L. Ed. 2d 568.

Cappelen, Herman, and Ernest Lepore. 2005. Insensitive semantics: a defense of semantic minimalism and speech act pluralism. Malden: Blackwell. 
Carson, Thomas L. 2010. Lying and deception: theory and practice. Oxford: Oxford University Press.

CSPL. 1995. Standards in public life: first report on the committee on standards in public life, vol. 1. London: House of Commons, Parliament.

Davidson, Donald. 1986. A nice derangement of epitaphs. Truth and interpretation: perspectives on the philosophy of Donald Davidson, 433-446. Ernest Lepore, ed. Cambridge: Blackwell.

Fallis, Don. 2009. What is lying? Journal of Philosophy. 106(1): 29-56.

Fallis, Don. 2010. Lying and deception. Philosopher's Imprint 2010(11): 1-22.

Fried, Charles. 1978. Right and wrong. Cambridge: Harvard University Press.

Grice, Paul. 1957. Meaning. Philosophical Review. 66: 377-388.

Grice, Paul. 1989 [1967]. Logic and conversation. In Studies in the way of words, 3-143. Cambridge: Harvard University Press.

Hawley, Katherine. 2012. Trust: a very short introduction. Oxford: Oxford University Press.

Kant, Immanuel. 1997 [c.1784]. Lectures on ethics, eds. J. B. Schneewind and P. Heath; P. Heath, trans. Cambridge: Cambridge University Press.

Laurence, Stephen. 1996. A Chomskian alternative to convention-based semantics. Mind. 105(418): 269-301.

Lewis, David K. (1975) Languages and Language. In Minnesota studies in the philosophy of science, ed. K. Gunderson, 3-35. University of Minnesota Press.

Meibauer, Jörg. 2014. Lying at the semantics-pragmatics interface. Berlin: De Gruyter Mouton.

Montaigne, Michel de. 1907 [1595]. Des menteurs. In Essais de Montaigne, Vol. 1, essay 9. Paris: Firmin-Didot.

Recanati, Francois. 2004. Literal meaning. Cambridge: Cambridge University Press.

Reynolds, Henry Robert. 1889. Athanasius: his life and his life-work. London: Religious Tract Society.

Saul, Jennifer M. 2012a. Just go ahead and lie. Analysis 72(1): 3-9.

Saul, Jennifer M. 2012b. Lying, misleading, and what is said: an exploration in philosophy of language and in ethics. Oxford: Oxford University Press.

Schiffer, Stephen. 1987. Remnants of meaning. Cambridge: MIT Press.

Schiffer, Stephen R. 1972. Meaning. Oxford: Clarendon Press.

Searle, John R. 1969. Speech acts: an essay in the philosophy of language. Cambridge: Cambridge University Press.

Searle, John R., and Daniel Vanderveken. 1985. Foundations of illocutionary logic. Cambridge: Cambridge University Press.

Shiffrin, Seana Valentine. 2014. Speech matters: on lying, morality, and the law. Princeton: Princeton University Press.

Simpson, David. 1992. Lying, liars and language. Philosophy and Phenomenological Research 52: 623-639.

Sorensen, Roy. 2007. Bald-faced lies! Lying without the intent to deceive. Pacific Philosophical Quarterly 88(2): 251-264.

Stojanovic, Isidora, ed. (2008) Special Issue of Synthese: ‘The semantics/pragmatics distinction'. 165(3).

Summers, Ben. 2008. The Fraud Act 2006: has it had any impact? Amicus Curiae: Journal of the Society for Advanced Legal Studies. 75(Autumn): 10-18.

Webber, Jonathan. 2013. Liar! Analysis. 73(4): 651-659.

Williams, Bernard. 2002. Truth and truthfulness: an essay in genealogy. Princeton: Princeton University Press.

Publisher's Note Springer Nature remains neutral with regard to jurisdictional claims in published maps and institutional affiliations. 